\title{
Metaficción historiográfica y autoficción: diferentes compromisos con la referencialidad en Estação das Chuvas de José Eduardo Agualusa y Soldados de Salamina de Javier Cercas
}

\author{
MAURO CAVALIERE
}

\begin{abstract}
Historiographic metafiction and autofiction: different commitments with the referentiality in Estação das Chuvas by José Eduardo Agualusa and Soldiers of Salamina by Javier Cercas.

This article offers a comparative analysis of the novels Estação das Chuvas (1996) by the Angolan writer José Eduardo Agualusa (born in 1960) and Soldados de Salamina (2001) of the Spaniard Javier Cercas (born in 1962). The two novels belong to different geographical and cultural contexts. Nevertheless, a common sensibility - due perhaps to the same generational affiliation or to the prevalence of topics in force in the 1990s - makes evident the emergence of both a historical theme and the presence of a subject involved in historical processes. Ultimately, in both novels, we come across a subject that makes history although in quite different ways: involved firsthand in historical events with tragic implications, in the case of Agualusa, and absorbed in a reflection on apparently distant events in the case of Cercas. However, the result of the emphasis on the presence of a subjectivity within historical processes causes the two novels to share a common element, that is, a double generic affiliation. Both Estação das Chuvas and Soldados de Salamina actually share semantic traits that make it possible to classify them at the same time as autofictional novels and historiographic metafictions.

Despite their common architectural matrix, the two novels represent two very different expressions within these genres. This manifests itself at different levels: first, the treatment of the autofictional character and, secondly, the treatment of the other characters. Through the analysis of the characters that populate these two novels, I will try to show how the two writers adopt divergent attitudes regarding the degree of referentiality in their works and how they end up proposing two different poetic options. In the analysis of the characters, I consider it useful to introduce a taxonomy that, in addition to including already existing types (referential, historical, fictitious characters), introduces other types hopefully useful to the study of the currently abundant number of fictions that, through an ambiguous narrative pact, are located between fiction and faction.
\end{abstract}

Keywords: autofiction; historiographic metafiction; referencial character; historical character; Soldados de Salamina; Estação das Chuvas 


\section{Introducción}

Publicada en 2001, la novela Soldados de Salamina tuvo, también gracias a una entusiasta reseña de Vargas Llosa (2001), un éxito enorme, en España y fue traducida a más de veinte idiomas. Tanto es así que, dos años después de su publicación, se realizó una versión cinematográfica de la novela. El autor, Javier Cercas, nacido en 1962, se afirma como uno de los más representativos escritores de su generación. Tanto el dispositivo metaficcional como el autoficcional de su novela serán objeto de estudio por parte de varios académicos.

Ya mucho menos famosa a nivel internacional (así que merece la corta presentación que sigue) es la novela Estação das Chuvas (1996) del escritor angoleño José Eduardo Agualusa (n. 1960). Sin embargo, esta novela, junto a otra publicada al año siguiente (Nação Crioula, 1997), dio al autor una considerable notoriedad en el ámbito de las letras de lengua portuguesa, consagrándolo además como uno de los más importantes novelistas angoleños. En los años siguientes publica diez novelas más (además de varios libros de cuentos y crónicas) y en el momento actual su libro de mayor alcance internacional (Teoria geral do esquecimento, 2012) fue traducido a más de veinte lenguas.

En Estação das Chuvas, un narrador, por medio de algunas entrevistas, recorre la parábola existencial, política y cultural de una poeta e historiadora angoleña, Lídia do Carmo Ferreira, coetánea y compañera de muchos protagonistas de la lucha de independencia. La historia de Lídia, y más tarde la del periodista-narrador, se entrecruza con la dramática historia del país africano hasta el trágico epílogo del otoño de 1992 en que la protagonista desaparece en el clima de violencia de las primeras elecciones libres del país.

\section{Rasgos comunes entre las dos novelas}

La metaficción historiográfica. En primer lugar, conviene examinar los rasgos comunes de las dos novelas y justificar su doble clasificación genérica a partir de otras definiciones acreditadas. Como es casi inevitable, cualquier estudio sobre las metaficciones historiográficas tiene que mencionar a la investigadora que fue responsable de la difusión internacional de esta etiqueta genérica, es decir, Linda Hutcheon que ya hace algunas décadas así la definía: "those wellknown and popular novels which are both intensively self-reflexive and yet paradoxically also lay claim to historical events and personages" (1988: 5). Sin embargo, en lo que se refiere a nuestro propósito, la definición de Hutcheon, que no analiza sólo novelas históricas, resulta demasiado amplia. Por el 
contrario, la restricción hecha, siempre a partir de la propuesta de esta autora por Fernández Prieto (1998: 150), resulta más eficaz ya que la investigadora española distingue entre dos tipos de novelas históricas innovadoras. Un primer tipo que se caracteriza por fenómenos tales como, la distorsión de material histórico, la propagación de historias alternativas o apócrifas y la exhibición de los procedimientos hipertextuales y un segundo tipo en que la metaficción constituye el eje temático y formal de la novela. Obviamente, la tipología más relevante en los casos aquí considerados es la segunda, porque trata de novelas que desde el punto de vista estructural acaban por crear dos planos narrativos distintos (el de la narración y de la meta-narración) y, desde el punto de vista ideológico, destacan la dimensión necesariamente subjetiva y parcial del relato, recordando constantemente al lector que el texto es un artefacto.

No cabe duda de que Soldados de Salamina pertenece al género metaficcional (Lluch Prats 2004; Gómez Trueba 2009), pues el episodio reconstruido de la ejecución de Sánchez Mazas, que es el núcleo narrativo (e histórico) de la novela, ni siquiera llega a ocupar la mitad del libro. Se trata, en efecto, de toda la segunda parte de las tres que constituyen la novela, mientras que en la primera parte se trata de la manera en que el narrador llega a conocer el acontecimiento principal y en la tercera el asunto trata de la búsqueda y el hallazgo del héroe que ha salvado la vida al intelectual falangista.

En lo que se refiere a Estação das Chuvas, el uso de procedimientos metaficcionales sólo es detectable claramente en los primeros capítulos de la novela, es decir, cuando la historia personal y pública (política y cultural) de la protagonista, Lídia do Carmo Ferreira, es reconstituida a partir de las entrevistas realizadas por el narrador en diferentes épocas. Sin embargo, a partir de la mitad de la novela, la secuencia cronológica de los acontecimientos relacionados con la historia de la Angola independiente se entrecruza con la historia personal del narrador.

La autoficción. Si las décadas de 1980-90 fueron caracterizadas por el florecer de estudios sobre la novela histórica y la metaficción historiográfica, la década siguiente y la actual parecen dedicar su atención al fenómeno de la autoficción ${ }^{1}$. Nuestra referencia privilegiada, en lo que concierne al concepto de autoficción, será El pacto ambiguo. De la novela autobiográfica a la autoficción de Manuel Alberca (2007). Se trata de un estudio documentado y conceptualmente

Una bibliografía exhaustiva de los estudios sobre la novela histórica se puede encontrar en Cavaliere (2002). Por otra parte, Toro (2017) proporciona una vasta y actualizada bibliografía sobre el tema de la autoficción. 
riguroso sobre el concepto en cuestión que además tiene la ventaja de proporcionar un modelo inclusivo por lo que se refiere a la identidad de sujeto autoficcional. Para desarrollar cualquier consideración con respecto a eso, se hace indispensable citar al autor:

La autoficción se presenta como una novela, pero una novela que simula o aparenta ser una historia autobiográfica con tanta transparencia y claridad que el lector puede sospechar que se trata de una pseudo-novela o una pseudo-autobiografía [...] su transparencia autobiográfica proviene de la identidad nominal, explícita o implícita del narrador y/o protagonista con el autor de la obra. (Alberca 2007: 128, cursiva nuestra)

El modelo de Alberca resulta más amplio precisamente porque incluye en su definición también el caso de la identidad nominal implícita, impidiendo así la exclusión de novelas cuyo carácter autoficcional es bastante evidente aunque el nombre del autor no se mencione explícitamente en el texto, que es el caso de Estação das Chuvas.

\section{Rasgos divergentes}

En lo que se refiere a las obras aquí analizadas, justamente el estatus implícito vs. explícito del narrador autoficcional es el primer rasgo que marca la primera de toda una serie de divergencias. En lo que se refiere a Soldados de Salamina, la identidad nominal es explícita, al menos a partir de la tercera parte de la novela ${ }^{2}$, lo que es evidente en los episodios de la entrevista con Bolaño y de la llamada telefónica con Miralles:

- Oye, ¿̇ú no serás el Javier Cercas de El móvil y El inquilino?

El móvil y El inquilino eran los títulos de los dos únicos libros que yo había publicado, más de diez años atrás (Cercas 2010: 143).

Miralles se rio de buena gana.

- Mire, Cercas ¿O tengo que llamarle señor Cercas?

- Llámeme Javier. (Cercas 2010: 174)

2 Recordamos que Soldados de Salamina está dividido en tres partes: "Los amigos del bosque” (pp. 13-72), “Soldados de Salamina” (pp. 73-138) y “Cita en Stockton” (pp. 141-207). Ninguna de las tres partes está subdividida en capítulos. 
Al principio de la novela el juego consiste en sugerir tanto la identidad como la disociación entre autor/narrador/personaje (de aquí en adelante A/N/P) como el contrario. De hecho, ya en el incipit se hace referencia a dos libros publicados por el autor en 1989 y 1987, pero poco más tarde se atribuye al narrador, en el año 1994, la edad de cuarenta años (Cercas 2010: 15-16), cuando Javier Cercas tenía treinta y dos, como se puede deducir de la ficha biográfica de la cubierta.

El caso de Estação das Chuvas es un poco más complicado, justamente debido a la falta de identidad nominal entre autor y narrador/personaje. El modelo flexible propuesto por Alberca permitiría incluirlo en el género autoficcional, pero hay que examinar cuáles son los (otros) elementos que plantean alguna sospecha con respecto a esta identidad. Antes de entrar en mérito de esta cuestión, es mejor proporcionar una rápida descripción estructural de la novela.

Como ya se ha señalado, lo que resalta es el cambio de protagonista en medio de la novela: hasta el capítulo IV, por un total de $\mathrm{IX}^{3}$, la protagonista es la poeta Lídia do Carmo Ferreira, cuyo recorrido existencial, intelectual y político es narrado por un periodista que, aparentemente, ya la entrevistó varias veces, en particular en el año 1990. La presencia muy discreta del (yo del) periodista-narrador cambia radicalmente de carácter cuando, en el párrafo 6 del capítulo V, él irrumpe en el relato, para reaparecer en el VI / 2 y desempeñar cada vez más el papel de protagonista en los demás capítulos VII, VIII, IX. Lídia do Carmo no desaparece del relato, pero sin duda ocupa una posición más periférica, siendo en el último capítulo un personaje ausente: todos la buscan sin encontrarla. En otras palabras, la homodiégesis que domina los primeros cuatro capítulos se transforma, después de alguna vacilación en el capítulo VI, en autodiégesis.

Sin embargo, volviendo al concepto de autoficción, si no hay identidad nominal explícita ¿cómo podemos establecer una eventual correspondencia A/N/P? Como ya se ha constatado en el caso de Soldados de Salamina, estas revelaciones suelen manifestarse in media liber, que también es el caso de Estação das Chuvas. En las primeras líneas de V/6 el lector vuelve a ser situado temporalmente en el mismo día en que comienza la novela (I/1), o sea, la noche del 11 de noviembre de 1975, cuando Agostinho Neto declara la independencia en una Luanda rodeada por fuerzas adversarias, el FNLA y el

3 La novela está divida en nueve capítulos no numerados que aquí señalamos con números romanos. Cada capítulo, excepto el noveno, está dividido, a la vez, en un número variable de párrafos numerados con cifras árabes. En este artículo, para referirse a diferentes trozos textuales, se adopta esta notación: capítulo / párrafo. V/6 es, por tanto, el sexto párrafo del quinto capítulo. 
ejército sudafricano. Por añadidura, si los primeros cinco párrafos del capítulo $\mathrm{V}$ se desarrollan en Luanda, en el capítulo V/6 el lector se encuentra de repente en otra ciudad angoleña, Huambo:

Enquanto o Presidente discursava no Largo Primeiro de Maio, Zorro avançava para Paulete [...] e depois cumprimentava Borja Neves. Enquanto Lídia pensava na morte, fechada no seu quarto, [...] eu preparava-me para fugir do Huambo (Agualusa 2007: 141, cursiva nuestra).

No es difícil entender que el sujeto de primera persona singular, "eu”, corresponde al mismo "yo" del narrador, sobre cuya vida no sabemos nada a lo largo de los primeros cuatro capítulos del libro, excepto que es un periodista que entrevistó a Lídia do Carmo Ferreira en 1986 (III/2), en 1988 (I/2) y en 1990 (II/2 y 11, III/8).

La diferencia es que, a partir de aquí, el papel de este anónimo personaje no será limitado al de biógrafo de Lídia, pues el periodista empieza a participar en la acción. Lo que se sabe de él es, por empezar, que el 11 de noviembre de 1975 estaba en Huambo. Por lo demás, dos páginas después, el (futuro) periodista deja el siguiente mensaje para su abuela:

Avó, quando leres isto já eu estarei muito longe. Vou juntar-me ao MPLA para combater pela nossa terra. Sei que tu compreendes. Diz-lhes [ao pais] que nos voltaremos a encontrar quando todos os fantoches tiverem sido corridos e Angola for livre. Saudações revolucionárias. Estão-se a rir? Em 1975 eu tinha quinze anos e isto não era ridículo (Agualusa 2007: 143).

Así que el lugar y la fecha de nacimiento del narrador (viene de Huambo, nació en 1960) son proporcionados en el texto de la novela y curiosamente corresponden con las del autor, como cualquier lector puede deducir del peritexto, pues en la solapa se puede leer lo siguiente: "José Eduardo Agualusa nasceu na cidade do Huambo, em Angola, a 13 de dezembro de 1960”.

Establecida la posible equidad entre A/N/P en Estação das Chuvas, debe subrayarse que, aun cuando se trata de un caso de autoficción, ésta es generada por un procedimiento diferente con respecto a Soldados de Salamina. Como se verá, esto depende de un enfoque muy diferente entre los dos escritores: en el caso de Agualusa mucho más volcado hacia un pacto ficcional y en el caso de Cercas, dominado por una adherencia a lo factual. Eso genera además una tipología bastante variada de personajes, que es lo que se analizará en los párrafos siguientes. 
Metaficción historiográfica y autoficción

Los personajes

El personaje disfrazado. Un rasgo que llama la atención y que distingue Estação das Chuvas con respecto a Soldados de Salamina es la "promiscuidad" entre dos diferentes categorías de personajes, los históricos y los inventados. En la primera parte de Estação das Chuvas de hecho interactúan con la protagonista, Lídia do Carmo Ferreira, una serie de personajes históricos que fueron protagonistas de las luchas anticoloniales africanas: Amílcar Cabral, Mário Pinto de Andrade y Viriato da Cruz, mientras que en la segunda, protagonizada por el narrador-periodista, los personajes no son históricos. La historicidad del personaje, depende, al fin y al cabo de la reconocibilidad del personaje (Reis 1992: 145; Sorin 1996: 126 y 127). El concepto de la reconocibilidad como conditio sine qua non para la existencia de un personaje referencial remonta a Hamon (1972: 95), cuando éste afirmaba que los personajes referenciales remiten al sentido fijo inmovilizado por una cultura y que su legibilidad depende del grado de participación del lector en ella. Esto inevitablemente remite a una dimensión receptiva lo que sin duda plantea algún problema, sobre todo en un contexto de la circulación internacional del texto literario.

La enciclopedia del lector puede de hecho variar mucho de un contexto histórico-cultural a otro y es algo difícil de establecer de forma definitiva visto que implica todas las posibles variantes diacrónicas, diatópicas y diastráticas. La intermediación literaria, en alguna medida, aparta el inconveniente de la falta de información enciclopédica esencial y, sin duda el acceso inmediato a la gran enciclopedia de la web facilita la verificación de la existencia extratextual de los personajes. Sin embargo, creemos que se puede considerar a manera de principio operativo a la hora de discriminar entre personajes referenciales e inventados, el alcance más o menos vasto, previsto por la difusión de una novela.

Más concretamente, si no es difícil reconocer como históricos los protagonistas de las luchas independentistas africanas arriba mencionados, es muy difícil en el caso de los que pueblan la segunda parte de la novela y que, por lo tanto (y por el momento), se podrán considerar como inventados (o "nativos" en la terminología usada por Pavel, 1986: 29).

Mi hipótesis es que, sin embargo, estos personajes merecen el título de "disfrazados". Como afirma Alberca (2007: 204-205) pues, es típico de la autoficción invitar el lector a una lectura referencial y al mismo tiempo alejarlo de ella. Por eso, planteada la sospecha - inherente a todo texto autoficcional de que Estação das Chuvas pueda ser un texto autobiográfico, la pregunta 
sobre la existencia "real" de los personajes que protagonizan los capítulos V-IX tiene alguna legitimidad. De hecho, tales sospechas llevaron a algunas investigaciones detectivescas interesantes a intentar adivinar quién se podía esconder detrás de uno u otro de los personajes que actúan en la segunda parte de la novela, como fue en el caso del investigador que se cita ahora:

Em todo caso, aventamos a possibilidade de haverem também personagens modeladas em figuras reais, como são os casos de Rui Tavares Marques, que sugere a figura de Manuel Rui Monteiro, e de Zorro, cuja trajetória política se aproxima bastante à de Nelson Eduardo Pestana (Silva 2012: 16).

Es el propio pacto ambiguo que invita a una lectura referencial y por eso detrás de Borja Neves, Zorro y Tavares Marques se puede llegar a identificar a unos personajes más o menos conocidos en la micro-historia de Luanda, tentación que imagino irresistible para los lectores de aquel país y de aquella misma generación.

Es importante destacar por lo demás que el personaje disfrazado, a diferencia del personaje histórico, debe su referencialidad a un signo semiótico diferente del personaje. Si a este signo pertenecen, además del nombre, su descripción física y psicológica, su identificación se debe también - y tal vez más - a otro signo, es decir, el de la acción. De cualquier modo, no se debe a su nombre pues el nombre ficticio desempeña un papel opuesto a la reconocibilidad, que es demandada en este caso al conocimiento de la actuación y otros rasgos que el lector puede eventualmente (re)conocer.

El personaje disfrazado no es evidentemente una expresión genuina de los géneros literarios que aquí se examinan. No son infrecuentes casos análogos, por ejemplo, en la narrativa del realismo decimonónico ${ }^{4}$, o en la literatura hispanoamericana del post-boom ${ }^{5}$, sin embargo considero que el pacto ambiguo de géneros como la novela histórica o la autoficción refuerza su estatus indeterminado. El reconocimiento en este caso no lleva a la simple constatación de la existencia de un modelo que hubiera podido inspirar este

4 A este propósito es interesante el caso de un personaje de Os Maias (1888) del escritor realista portugués Eça de Queirós, el poeta Tomás de Alencar, que parece modelado sobre la figura del poeta ultra-romántico Bulhão Pato (Reis 2015).

5 En La casa de los espíritus de Isabel Allende hay por lo menos dos personajes disfrazados, el cantor Pedro Tercero García que recuerda a Victor Jara y el médico Jaime Trueba, en que es reconocible el médico personal de Salvador Allende, Arturo Jirón. Se trata de referencias sugeridas vagamente por la caracterización de estos personajes cuya acción, sin embargo, no coincide casi para nada con lo que ocurrió en el plano histórico (Correas Zapata 1998). 
Metaficción historiográfica y autoficción

tipo de personaje, sino que puede llevar a preguntarse si y cuánto de lo que hacen y dicen corresponderá a la realidad o si el uso de un nombre ficticio no será simplemente un estratagema para preservar, además de la libertad del escritor, la privacidad de las personas que se representan en una novela (incluso para evitar todas las consecuencias que tales operaciones pueden conllevar en el plano jurídico $\left.{ }^{6}\right)$.

El personaje contrabandeado. En la novela Beatus Ille de Muñoz Molina, el protagonista, Minaya, al investigar sobre la vida de Javier Solana, un escritor y militante republicano, descubre una fotografía tomada durante el cerco de Madrid, cuya descripción se cita a continuación:

El Mono Azul [...] jueves, 1 de octubre de 1936, el rectángulo negro de una foto indescifrable: Rafael Alberti, José Bergamín y Jacinto Solana en las dependencias del Quinto Regimiento (Muñoz Molina 2009: 24, cursiva original).

Probablemente el episodio fue inspirado por una famosa fotografía en la que, en vez del protagonista inventado por el autor, aparece Manuel Altolaguirre ${ }^{7}$. Como se ve, la fotografía se menciona al principio de la novela, mientras que la identidad ficticia de Solana puede ser deducida por la increíble e inverosímil parábola existencial del poeta y soldado republicano. El ardid, o sea la ambigüedad, depende de que al aparecer en un documento en el que se retratan dos famosos intelectuales republicanos, se comunica la sensación que también el protagonista es tal.

No procede de manera diferente Agualusa al colocar a la protagonista inventada, Lídia do Carmo Ferreira, al lado de muchos personajes históricos presentes en la primera parte de Estação das Chuvas (capítulos I-IV).

A sua melhor amiga, Antónia Buriti, estava apaixonada por um colega de turma [...] Lídia achava-a ridícula [...] mas na realidade sentia ciúmes dela. O motivo de tanta exaltação sentimental era um mulato escuro [...] chamava-se Viriato Francisco Clemente da Cruz [...] Lídia tinha reparado nele [...] um dia escreveu no seu diário, VI-RI-ATO. VITORIA. [...] Às vezes sonhava com ele (Agualusa 2007: 55-56).

6 Se trata del caso, referido por Alberca (2007: 107-8), de la escritora española Luisa Castro, algo que Genette (1993: 70) definiría como "autobiografía vergonzosa".

7 Puede ser visionada en el sitio del Instituto Cervantes: http://www.cervantesvirtual. com/portales/rafael_alberti/album_de_fotos/ 
Começou tudo com uma grande discussão sobre a negritude. Mário Pinto de Andrade pretendia incluir alguns poemas de Lídia numa coletânea de poesia negra de expressão portuguesa (Agualusa 2007: 80)

Colocar Solana al lado de Bergamín y Alberti o colocar Lídia do Carmo Ferreira en la misma clase de Viriato da Cruz, así como representar a Mário Pinto de Andrade que pide poemas a la protagonista para su revista, es más o menos como contrabandear a un mundo referencial un personaje inventado ${ }^{8}$ creando la ilusión - incluso la creencia, por lo menos durante algún tiempo - que estos personajes gozan también del mismo estatus de los personajes históricos 9 .

Naturalmente este procedimiento es inherente a la novela histórica desde su nacimiento y bien se podría objetar que, por el hecho de que don Abbondio converse con el cardenal Federigo Borromeo, el lector de I promessi sposi (Manzoni, cap. XXV) no cree ciegamente en la existencia del pávido cura de un pueblo de provincias. Sin embargo, además de no ser prudente confiar ciegamente en la franqueza del pacto de lectura establecido por Manzoni - y por lo general, todos los autores de novelas históricas del romanticismo con sus lectores ${ }^{10}$, dos siglos de investigación organizados en un saber ya institucionalizado nos informan y orientan sobre estas obras canónicas, lo que

8 Se entiende por personaje inventado todo tipo de personaje que, siendo "bautizado" por el escritor, nace en un texto ficcional por primera vez. Decimos bautizados justamente porque el nombre que se le atribuye vuelve imposible o muy difícil su identificación con el mundo actual (v. Pavel 1986: 46-47). Se prefiere esta denominación a la de "personaje ficcional" porque todo tipo de personaje (incluso el referencial) sufre un cierto grado de ficcionalización.

9 La creencia puede incluso durar mucho tiempo, incluso décadas, y no solamente por parte de lectores ingenuos. En una reseña escrita en uno de los diarios más importante de Portugal diez y seis años después de la publicación de Estação das Chuvas, puede leerse lo siguiente: "Ainda hoje, de vez em quando, José Eduardo Agualusa encontra alguém que pensa ter conhecido Lídia do Carmo Ferreira e ter dados sobre o seu paradeiro" (Marques 2012). Por otro lado, también en ámbito académico, hay quien afirma que Lídia es un personaje "histórico - real" (Machado 2010: 60). Sin embargo, Tibério (2013), con una lectura cuidadosa del paratexto, aclara que Lídia do Carmo Ferreira es una invención de Agualusa.

10 No se olvide que Manzoni, siguiendo una convención típica de la novela histórica, afirma, en la introducción de Los Novios, que la historia ahí narrada es sacada de un manuscrito anónimo del siglo XVII. Por demás afirma que, investigando sobre este mismo siglo, encontró noticias de personajes históricos de que tan sólo había tenido noticia por primera vez en el manuscrito al punto de dudar si jamás hubieran existido (Manzoni 1987: 2-3). Como se ve, el peritexto orienta a un pacto narrativo de tipo verídico. 
Metaficción historiográfica y autoficción

no ocurre en las novelas aquí examinadas, una de las cuales, como se verá, dio lugar a un divertido y, sobre todo, edificante equívoco.

Personajes rescatados. Después de la publicación de la novela (2001) y el rodaje de la película basada en la novela (2003), se publicó un libro en el que se transcribe un largo diálogo entre el director de la película, David Trueba, y Javier Cercas. El libro, acompañado por una impresionante documentación fotográfica, constituye una agradable e instructiva lectura, constituyendo un epitexto de gran valor, especialmente por ser un caso en que Javier Cercas expone explícitamente la poética de Soldados de Salamina, y quizá la poética que soportó su actividad novelesca de los años siguientes.

Citamos un pasaje en que Javier Cercas se expresa sobre el uso de los nombres propios, tanto del autor como de los personajes:

JC: En la novela, el autor y el narrador tenían que llevar el mismo nombre DT: ¿por qué?

JC: Por muchísimas razones, entre otras porque si todo el mundo - Sánchez Mazas, los Figueras, Ferlosio, Trapiello, Bolaño, etc. - aparecía con su nombre real, hubiera sido una incongruencia total que el autor no apareciera también con el suyo; si hubiera hecho eso, todo el mecanismo literario hubiera dejado de funcionar (Cercas \& Trueba 2004: 94).

"El mecanismo literario", la poética, es en efecto muy diferente en relación a la que domina en Estação das Chuvas. El respeto por el "nombre real" es llevado al extremo. Parece casi que, con la excepción de pocos personajes inventados, todos los personajes llevan (porque tienen que llevarlo), el nombre de pila. No es sorprendente por eso que algunos lectores interpretaran al pie de la letra todas las acciones y los personajes de la novela.

A este propósito vale la pena aludir al inicio de la entrevista en que Javier Cercas, después de citar lo que el narrador de Soldados de Salamina afirma en el implicit de la novela (transcrito entre comillas en nuestra cita), explica cómo mucho de lo que se afirma en aquellos pasajes no corresponde a la realidad:

"tres cosas acababan de ocurrirme por entonces: la primera es que mi padre había muerto; la segunda es que mi mujer me había abandonado; la tercera es que yo había abandonado mi carrera de escritor". La verdad es que mi padre no ha muerto, aunque de vez en cuando algún lector se le acerca y le pregunta: "Pero, ¿usted no estaba muerto?" y más de uno le da el pésame a mi madre. Tampoco es verdad que mi mujer me haya abandonado, por lo menos hasta esta tarde: otra cosa es que se lo plantee cada vez que alguien la llama Conchi, tomándola por el personaje que en la novela tiene una relación con el narrador. 
$\mathrm{Ni}$ siquiera es cierto que trabaje en un periódico como el protagonista de la novela. (Cercas 2010: 11)

Por supuesto, si esto se debe a la ingenuidad de algunos lectores (¿cuántos? por lo visto no fueron pocos), es igualmente cierto que el pacto narrativo ambiguo llevado a tales extremos por Javier Cercas contribuyó a ello. Leyendo Diálogos de Salamina, se constata que Javier Cercas respeta religiosamente la identidad nominal permitiéndose, por el contrario, cambiar muchos elementos a nivel de la acción, en particular en lo que se refiere a los dos protagonistas de la novela, el narrador y el héroe.

Esto no deja de tener algunos efectos originales planteando algún problema en relación a la posible clasificación de los personajes, autorizando, creo, la introducción de otra categoría más allá de los personajes inventados, referenciales y disfrazados, es decir, la de los personajes rescatados. Para hacer esto más claro, resumimos en este cuadro cuatro categorías de personajes.

\begin{tabular}{|l|l|l|l|}
\hline Inventados & Históricos & Autoficcional & Rescatados \\
\hline Conchi & Sánchez Mazas, & Javier Cercas & Miguel Aguirre, \\
Françoise & Sánchez Ferlosio, & & Pere, Jaume y Joaquín \\
& Roberto Bolaño, & & Figueres, Daniel Angelats, \\
& Trapiello, Jesús Pascual & & María Ferré, \\
& Aguilar más & & Joan y Lella Segués, \\
& todos los personajes & & Miguel Cardos, Santi \\
& citados en la segunda & & Brugada, Jordi Badayoly \\
& parte, por ejemplo: & & naturalmente Miralles \\
& Lístery Togliatti. & & \\
\hline
\end{tabular}

No hay grandes dificultades en categorizar los de la columna número 2 como referenciales (históricos) ${ }^{11}$ sin ser muy difícil, para quien ya no los conozca, conseguir alguna información sobre ellos en otros textos anteriores a la novela incluso el casi desconocido Jesús Pascual Aguilar cuyo único libro se conserva en algunas bibliotecas ${ }^{12}$. También esta categoría separada que es el personaje autoficcional fue examinada, en cuanto a los personajes inventados, el epitexto confirma que nunca existieron Conchi y la Hermana Françoise, asistente de un asilo que el autor empírico nunca visitó.

11 V. Reis (1992: 145), Bal (1995: 91), Eco (1975: 125; 140; 161).

12 Por ejemplo en la Biblioteca Nacional, http://catalogo.bne.es/uhtbin/cgisirsi/?ps= 40eAaEK1WO/BNMADRID/164680535/5/0 
De todas maneras, ¿qué se puede decir sobre los personajes de la columna número 4? Se estableció, poco después del éxito editorial de Soldados de Salamina, que existen o existieron. Por lo tanto, ¿podemos considerar referenciales a "los amigos del bosque"? La cuestión es que si no es difícil conseguir un texto que nos hable de Sánchez Mazas, de su hijo, Ferlosio, de Trapiello o de Bolaño, no hay texto que nos atestigüe la existencia previa a Soldados de Salamina de un Daniel Angelats, a no ser el registro civil de Cornellá del Terri o el fragmentario y volátil discurso oral de sus habitantes. No hay (mejor dicho, no había) en efecto, fuera del limitado territorio de la comarca del Pla del Estany, algún conocimiento sobre estas personas, que a partir de $2001 \mathrm{y}$ sólo a partir de esta fecha, se transforman en personajes. Por ello, sólo los de la columna número 2 pueden considerarse referenciales. De cierta manera, el pacto ambiguo hace que, con la excepción de los personajes referenciales y autoficcionales, los otros personajes queden confinados en un limbo donde es difícil establecer algo cierto sobre su estatus, pero al mismo tiempo, como es evidente que se trata de un texto basado en investigaciones cuidadosas, acaba por sugerir que el escritor no ha inventado nada, lo que lleva directamente a malentendidos como la identificación del cónyuge "empírico" (se nos pase el nuevo concepto) de Javier Cercas con Conchi.

De todas maneras, es tan solo el epitexto que puede desambiguar el caso. El de Soldados de Salamina es de hecho un caso privilegiado porque la entrevista nos revela la existencia fáctica de "los amigos del bosque":

María Ferré, Quim Figueras y Daniel Angelats. Porque claro, yo los encontré como redimidos, con una vitalidad magnífica. Me han dicho que, en buena parte, gracias al libro, se sentían importantes, queridos [...] el hijo de Angelats me dijo que su padre iba a vivir cinco e seis años más gracias a esta historia (Cercas \& Trueba 2004: 62) [...]. Claro, para entonces ya eran conocidos, habían salido en los periódicos y las radios. (Cercas \& Truebas 2004: 67)

Puede parecer una cuestión ociosa, pero el dato sobre la existencia factual, pero no referencial, plantea algún problema teórico porque eso está determinado por el pacto narrativo establecido entre autor y lectores. Eso muestra que hay también otro aspecto que puede ser considerado a la luz de la dinámica establecida por la desambiguación del epitexto, es decir el hecho de que personajes que se pueden percibir como inventados, se revelan, por medio del testimonio autoral, como factuales. Es el caso de "los amigos del bosque" que desde el limbo de la ficción se elevan a los faustos de la realidad y, como notifica el pasaje citado arriba, de la fama. No sé si el término es muy feliz pero, 
justamente por pasar de una zona incierta a otra ya mejor definida, se podrían denominar como "personajes rescatados".

Rescates póstumos. Otro curioso desafío está constituido por el héroe de Soldados de Salamina. A partir de las informaciones textuales, el lector sabe que las noticias sobre su existencia se deben a Roberto Bolaño, que en el papel privilegiado de narrador intradiegético introduce la historia de Miralles. En resumen, Bolaño cuenta a Cercas la historia de un cliente del camping en el que el primero había trabajado a finales de la década de los setenta: se trata de un ex-soldado republicano residente en Francia desde hace años que había participado en la guerra civil española, después en la Segunda Guerra Mundial con la Legión Extranjera, en África, y luego con las tropas regulares en Europa, siendo finalmente herido en los últimos días de la guerra. Bolaño todavía recuerda su apellido, Miralles. En la novela, después de reiterados esfuerzos y gracias a la ayuda de Conchi, el Javier ficcionalizado llega a encontrar al anciano Miralles en un asilo de Dijon.

En la realidad, Javier Cercas renunció a buscar a Miralles casi inmediatamente e hizo algo que no coincide mínimamente con lo que pasa en la novela, o sea, siguiendo el consejo que Bolaño le da en la novela, lo inventó, es decir le atribuyó acciones no documentadas, pero siempre respetando la regla de retener el nombre transmitido por sus fuentes. La diferencia es que en este caso, antes de todo, se tiene poca información sobre Miralles; en segundo lugar, el personaje asume un papel destacado con respecto a otros; y finalmente hay que crear la ilusión que, en la medida de lo posible, se trate del soldado que le salvó la vida a Sánchez Mazas.

Como es bien sabido, en 2013 un tal Miguel Miralles, el hijo de un hombre cuyas hazañas bélicas tenían una impresionante semejanza con las que se narran en el libro, concedió unas entrevistas y en ellas reveló que su padre había muerto en 1991 y llegará, en la primavera de este mismo año, a participar en una mesa redonda con el mismo Javier Cercas (S/N 2013a).

En resumen, Javier Cercas, quien no pudo encontrar a Miralles, lo inventó. Sin embargo la poética "nominalista" de Soldados de Salamina hizo que al cabo de doce años, el propio personaje, o mejor dicho, su heredero, se encontrara con el escritor. En definitiva, Cercas al seguir un principio opuesto al de Agualusa, el de no insertar personajes disfrazados (Javier Cercas podría tranquilamente inventar un apellido catalán cualquiera para su héroe), creó las premisas de la revelación póstuma de la identidad de Miralles. Caso que, si no es único, es seguramente original e indudablemente paradójico. 
Personajes referenciales, autoficcionales (explícitos e implícitos), inventados, disfrazados, contrabandeados, fácticos, rescatados, sustitutos. Muchas categorías originadas por la complejidad de la novela posmoderna (Arnaut 2016: 25) o tal vez, como afirma Donnarumma (2014), por un tipo de novela que señala que ya se salió (¿ya?) del post-modernismo para desembocar en lo que el crítico italiano llama híper-modernidad. Personajes que de toda manera merecen una atención especial debido a la insuficiencia de categorías narratológicas generadas en las décadas anteriores.

\author{
Mauro Cavaliere \\ mauro.cavaliere@su.se \\ Romanska och klassiska institutionen \\ Stockholms universitet \\ SE-106 91 Stockholm \\ SVERIGE / SWEDEN
}

\title{
Referencias
}

Agualusa, J. E. 2007 [1996]. Estação das Chuvas. Lisboa: Dom Quixote.

Alberca, M. 2007. El pacto ambiguo. De la novela autobiográfica la autoficción. Madrid: Biblioteca Nueva.

Arnaut, A. P. 2016. A insólita construção da personagem post-modernista. - Abusões, 3, 2, 7-33. https://doi.org/10.12957/abusoes.2016.26284

Bal, M. 1995. Teoría de la Narrativa (Una Introducción a la Narratología). Madrid: Cátedra.

Bidaud, S. 2016. Pour une poétique du nom de personnage. - Interlitteraria, 21/1, 117129. https://doi.org/10.12697/IL.2016.21.1.10

Bolaño, R. 2000. Nocturno de Chile. Barcelona: Anagrama.

Cavaliere, M. 2002. As Coordenadas da Viagem no Tempo. Stockholm University.

Cercas, J. 2010 [2001]. Soldados de Salamina. Barcelona: Tusquets.

Cercas, J.; Trueba, D. 2004. Diálogos de Salamina. Barcelona: Tusquets.

Correas Zapata, C. 1998. Isabel Allende, Vida y espíritus. Plaza Janés: Barcelona.

Donnarumma. 2014. Ipermodernità. Dove va la narrativa contemporanea. Bologna: Il Mulino.

Eco, U. 1975. Trattato di semiotica generale. Milano: Bompiani.

Fernández Prieto, C. 1998. Historia y novela: poética de la novela histórica. Pamplona: Eunsa.

Genette, G. 1991 [1993]. Ficción y dicción. Barcelona: Lumen.

Gómez Trueba, T. 2009. 'Esa bestia omnívora que es el yo': el uso de la autoficción en la obra narrativa de Javier Cercas. - Bulletin of Spanish Studies, 86, 1, 67-83. https:// doi.org/10.1080/14753820802696782 
CAVALIERE

Hamon, Ph. 1972. Pour un statut sémiologique du personnage. - Littérature, 6, 86-110. https://doi.org/10.3406/litt.1972.1957

Leiduan, A. 2014. Quand des pages de roman deviennent... des pages d'histoire. Cahiers de Narratologie, 26, 1-20. https://doi.org/10.4000/narratologie.6823

Lluch Prats, J. 2004. La dimensión metaficcional en la narrativa de Javier Cercas. Centro Virtual Cervantes. https://cvc.cervantes.es/literatura/aispi/pdf/19/I_21. $\operatorname{pdf}(17.03 .2019)$.

Machado, A. 2010. Estação das Chuvas. Um diálogo entre História e Literatura. Mulemba, 1, 7-33. https://doi.org/10.35520/mulemba.2010.v2n3a4852

Manzoni, A. 1987 [1842]. I promessi sposi. Milano: Hoepli.

Marques, S. M. 2012. À procura de uma poeta e da esperança angolana. - O Público, 1 de setembro https://www.publico.pt/2012/09/01/jornal/a-procura-de-umapoeta-e-da-esperanca-angolana-25169730 (17.03.29).

Muñoz Molina, A. 2009 [1986]. Beatus Ille. Barcelona: Seix Barral.

Pavel, T. 1986. Fictional Worlds. Cambridge (MA); London: Harvard UP.

Pessoas de livro. Estudos sobre a personagem. 2015. Coimbra: Imprensa da Universidade de Coimbra.

Reis, C. 1992. Fait historique et référence fictionelle: le roman historique.-Dedalus, 2, 141-147.

Silva, O. S. da. 2012. As marcas da violência: uma leitura de Estação das Chuvas, de José Eduardo Agualusa e Maio, mês de Maria de Boaventura Cardoso. Tese de mestrado, Universidade de São Paulo.

S/N. 2013a. Surt a la llum la identitat del mític Miralles de «Soldados de Salamina». - Diari de Girona, 9 de abril, s/p., http://www.diaridegirona.cat/cultura/ 2013/04/08/surt-llum-identitat-del-mitic-miralles-soldados-salamina/611998. html (19.10.2019).

S/N 2013b. Sale a la luz la identidad del mítico Miralles de «Soldados de Salamina». Información, 9/4, s/p.

Sorin, N. 1996. Le personnage-référentiel comme composante de la lisibilité sémiotique. - Sémiotique appliquée, 1: 2, 123-132.

Tibério, F. F. 2013. Contradição, história e política em Estação das Chuvas, de José Eduardo Agualusa. - Revista de Línguas \& Letras, vol. 14, n. 27, s/p.

Toro, V. 2017. Soy simultáneo. El concepto de autoficción en la narrativa hispánica. Madrid: Iberoamericana-Vervuert.

Vargas Llosa, M. 2001. El sueño de los héroes. - El País, 3 de septiembre https://elpais. com/diario/2001/09/03/opinion/999468046_850215.html (19.10.2019). 